\title{
Characteristic trajectories of ecosystem services in mountains
}

\author{
Bruno Locatelli ${ }^{1,2 *}$, Sandra Lavorel ${ }^{3}$, Sean Sloan ${ }^{4}$, Ulrike Tappeiner ${ }^{5,6}$, and Davide Geneletti ${ }^{7}$
}

Intensification of land use and management over recent decades has resulted in trade-offs between food or timber production and other ecosystem services (ES). Despite an increase in scholarly publications on ES, the temporal aspects of ES trade-offs have largely been neglected to date. Here we explore how past and future land-use trajectories (pathways of change) influence ES over time, using mountain landscapes as a model. Based on a synthesis of 51 cases of temporal changes in ES within mountain landscapes, we analyze how changes in land-use intensity influence the supply of ten key services and we describe six typical examples (archetypes) of ES change. Our analysis reveals that land-use intensity is an important factor shaping these archetypes. Land-use intensification often degrades ES (eg recreation and water regulation), with the exception of services targeted by intensification (food or timber) and with differences between forest and agricultural intensification. Service degradation following intensification is not always reversed by reductions in land-use intensity (termed "extensification").

Front Ecol Environ 2017; 15(3): 150-159, doi:10.1002/fee.1470

A though human modifications of ecosystems affect the flow of ecosystem services (ES), policy and management interventions can be designed to at least partially restore ES and their contribution to human well-being (MA 2005). However, the management of multiple ES across landscapes can be challenging, given that tradeoffs between services often occur over space and time (Raudsepp-Hearne et al. 2010; Locatelli et al. 2014), for

\section{In a nutshell:}

- Our analysis of case studies in mountains identifies six typical cases of changes in ecosystem services (ES) following changes in land-use intensity

- Land-use intensification often leads to declines in ES (eg recreation and water regulation), except for services targeted by intensification (food or timber) and carbon to a lesser extent, which diverge between tree and grass-dominated systems

- Services degraded by intensification may not be improved by subsequent reduction in land-use intensity

- Simple stylized models of the effects of land-use intensity on ES can be used to communicate trade-offs between services but should be adjusted to specific contexts

${ }^{1}$ CIRAD, Forests and Societies, Montpellier, France; ${ }^{2}$ Center for International Forestry Research, Climate Change, Lima, Peru *(bruno.locatelli@cirad.fr); ${ }^{3}$ CNRS, Laboratoire d'Ecologie Alpine, Université Grenoble Alpes, Grenoble, France; ${ }^{4}$ Centre for Tropical Environmental and Sustainability Science, College of Marine and Environmental Science, James Cook University, Cairns, Australia; ${ }^{5}$ Institute of Ecology, University of Innsbruck, Innsbruck, Austria; ${ }^{6}$ EURAC Research, Institute for Alpine Environment, Bolzano, Italy; ${ }^{7}$ Department of Civil, Environmental and Mechanical Engineering, University of Trento, Trento, Italy example, where increasing food production leads to decreases in regulating services. In contrast to the spatial dimension of ES, little attention has been paid to the temporal dimension of ES trade-offs (Holland et al. 2011; Bennett et al. 2015). Because critical land-use changes are anticipated in the future and competing demands on land imply trade-offs (Laurance et al. 2014), understanding the temporal changes in multiple ES caused by current and impending land-use is necessary to inform sound management decisions (Bennett et al. 2009), especially when these decisions are intended to re-establish complex services and restore biodiversity. Our aim is to contribute to this understanding by analyzing the temporal changes of multiple ES, using mountain landscapes as a model.

The temporal trajectories (or pathways of changes) of ES are typically driven by human activities that modify land use and cover (Lautenbach et al. 2011; Renard et al. 2015). Changes in land use and land cover may lead to changes in ES, both qualitative (converting forests to agricultural lands replaces timber with food production) and quantitative (water-quality metrics are negatively affected by increased fertilizer use with agriculture) (Foley et al. 2005. Land intensification (ie increase in land-use intensity) has been a major motivation behind land-management changes in the past 50 years, and has resulted in rapid increases in agricultural yields but has also lead to biodiversity losses (Lambin et al. 2000). Conversely, large areas in developed nations or in countries with transition economies (those proceeding toward market economies) have been recolonized by forest as a result of extensification (ie decrease in land-use intensity) or abandonment, leading to substantial improvements in biodiversity and carbon sequestration (Levers et al. 2015). Although often 
defined as the degree of agricultural input or output per unit of area and time (Turner and Doolittle 1978), land-use intensity can also be defined as the magnitude of impact of land-based production on biodiversity, water quality, or carbon (Erb et al. 2013).

Not surprisingly, research on land-use intensity has tended to focus on agriculture but has largely neglected the interface between agriculture and agroforestry or forest management (Lambin et al. 2000). Only a few studies on intensification have considered forestry or agroforestry (Erb et al. 2013); for example, Klein et al. (2002) described a sequence of increasing land-use intensity, from a near-

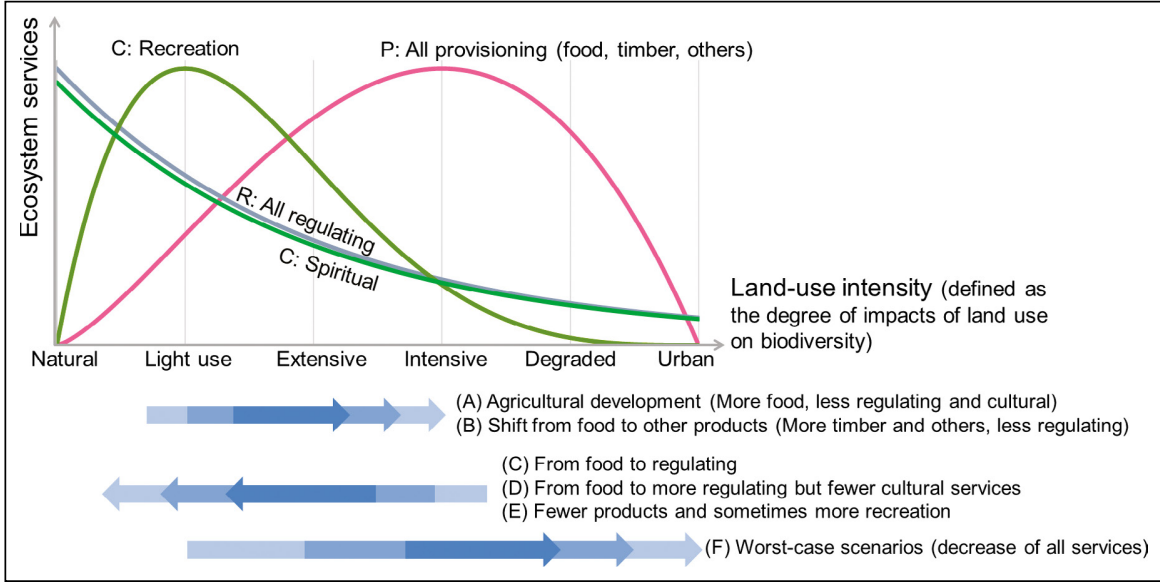

Figure 1. Stylized model (line graph) proposed by Braat and Ten Brink (2008) and De Groot et al. (2010), linking the supply of four types of ecosystem services (ES) to landuse intensity. $P=$ provisioning services; $R=$ regulating services; $C=$ cultural services. Archetypes of ES trajectories (A to F) in this model are shown below the graph's $x$ axis (arrows and accompanying text). natural forest to an intensively managed agroforestry system. It is worth paying more attention to the land uses that are in between agriculture and forestry, given the extensive and often increasing tree cover within agricultural landscapes (Schnell et al. 2015).

In attempting to determine an "optimal" spatial agricultural configuration for biodiversity conservation, previous studies have analyzed the nature of the relationships between agricultural intensity and biodiversity (Flynn et al. 2009; Kleijn et al. 2009; Balmford et al. 2012). Although valuable, such research is ultimately incomplete as land-use intensification affects biodiversity and multiple ES in a variety of ways (Tscharntke et al. 2005; Seppelt et al. 2013). Any configuration considered "ideal" specifically for biodiversity may be sub-optimal for ES. Additional research is needed to clarify the overall effects of intensification on ES in diverse landscapes that include agriculture and forest mosaics in order to guide land-allocation decisions in real-world contexts in which ES priorities compete with each other for attention (Swift et al. 2004; Erb et al. 2013).

Stylized models have been used in global or regional ES assessments to characterize the services supplied by various land management techniques (Burkhard et al. 2009; Schneiders et al. 2012). More specifically, Braat and Ten Brink (2008) proposed a stylized model - the only one of its kind - that shows how ES are affected by changes in land-use intensity (defined as the degree of impacts of land use on biodiversity) with six land-use classes ranging from natural to urban (Figure 1). In this model, provisioning services (eg food or fiber) were assumed to be negligible in natural unmanaged ecosystems and to reach a maximum in intensively used lands; in contrast, regulating services were optimal in natural ecosystems and decreased with intensification. In the case of cultural services, recreation services peaked in ecosystems with light use, whereas spiritual services were assumed to decrease with greater levels of land intensification (Braat and Ten Brink 2008; De Groot et al. 2010). The changes in ES across land-use intensities in Figure 1 can be interpreted as having both a temporal and spatial dimension, whereby different land covers with varying degrees of perturbation represent the temporal progression of degradation and disturbance in a single place. The temporal dimension of the model is amenable to elaboration and testing against empirical studies.

Mountain landscapes offer a valuable context in which to explore temporal trade-offs in ES associated with changing land-use intensity for two reasons. First, by virtue of their topography and climate, mountainous landscapes are key providers of certain ES - particularly water regulation, timber production, grazing, and recreation - that make substantial contributions to lowland and highland economies (Grêt-Regamey et al. 2012). Twenty percent of the world's population lives on mountains or in their foothills, and many more inhabit adjacent lowlands; all benefit from ES immediately derived from mountains (Marston 2008). Second, mountain and upland landscapes are undergoing and are expected to continue experiencing major changes in land use and ES provision (Schirpke et al. 2013; Crouzat et al. 2015). Mountains are hotspots of forest-transition dynamics across Latin America and Asia, the geography of recent forest regrowth is overwhelmingly described as "upland" or "marginal" (Asner et al. 2009; Lambin and Meyfroidt 2011). Likewise, forest recolonization following land abandonment or polarization of land use between valleys and uplands has substantially changed the appearance of European mountains (Zimmermann et al. 2010).

By describing archetypal ES trajectories and testing how temporal changes in land-use intensity influence 


\begin{tabular}{lll}
\hline Table 1. Ecosystem services & (ES) surveyed in reviewed studies \\
\hline ES category & Subcategory & Description \\
\hline Provisioning services & Food & Food from agricultural systems, including crops, meat, and milk \\
& Timber & Timber, wood, and fuel wood \\
& Others & Wild plants and animals \\
\hline Regulating services & Soil & Mass stabilization and control of soil erosion \\
& Water flow & Hydrological cycle and water flow maintenance, flood protection \\
& Water quality & Water purification and filtration \\
& Carbon & $\begin{array}{l}\text { Global climate regulation by reduction of greenhouse-gas } \\
\text { concentrations }\end{array}$ \\
\hline Cultural services & Spiritual & Emblematic or sacred plants and animals, ritual identity, artistic \\
& representations of nature \\
& Use of ecosystems for walking, hiking, climbing, leisure hunting \\
& Heritage & Historic records, cultural heritage, sense of place \\
\hline
\end{tabular}

the supply of and trade-offs between multiple ES, we profile the diversity of temporal trajectories of ES in mountain landscapes. We base our model on a review of case studies conducted in these landscapes and a synthesis of case study observations along a gradient of landuse intensity.

\section{Materials and methods}

We surveyed and analyzed studies on changes to ES in mountainous landscapes to identify innate "clusters" of ES change. These clusters define a typology (classification scheme) of ES change in mountain contexts and are characterized by the synthesis of their constituent studies. This typology serves to test and expand popular conceptual models of ES change.

\section{Selection and analysis of case studies}

In January 2016, we searched Web of Science and Scopus literature databases for peer-reviewed studies quantifying historical dynamics of multiple (ie at least two) ES in mountain landscapes. Our search technique relied on three groups of keywords linked with the AND operator, namely: geographic keywords (eg mountain* OR highland*) AND subject keywords (eg "ecosystem service*" OR "ecosystem function*") AND approach keywords (eg history OR change) (see WebPanel 1 for additional details). This search yielded 844 studies and, after removing duplicates and reviewing abstracts or full texts, we retained 30 studies that assessed (with measurements or models) changes in two or more services at a landscape scale over periods greater than 5 years. Many of these studies surveyed several sites or several periods; thus, the 30 studies resulted in 51 cases (ie a given site over a given time period).

\section{Analysis and ES change typology}

For all 51 cases, we coded the reported temporal changes of ten key ES (three provisioning services, four regulating services, and three cultural services; Table 1) in four categories (increase, decrease, no change, or missing information). Given the diversity of metrics used to assess ES in the reviewed studies and the varying level of detail in the results reported by those studies, we could not apply a qualitative meta-analysis.

The ten categorical variables describing temporal changes of ES were used for clustering the 51 cases (WebPanel 2 and WebTable 1). We found that the optimal number of clusters was seven using the NbClust package in $\mathrm{R}$ (Charrad et al. 2014), which identifies the optimal number of clusters after testing 30 indices of clustering performance. We performed hierarchical cluster analysis using hclust in the stats package in R ( $R$ Core Team 2014). Because results were sensitive to clustering options, we combined five agglomeration methods (ward.D, ward.D2, complete, average, and mcquitty) with two distance measures (euclidean and manhattan), resulting in 10 different clustering outcomes. If a case fell within the same cluster in more than two-thirds of the clustering outcomes, we considered that this case was an archetype (ie a very typical example) of the cluster.

\section{Results}

\section{Overview of the archetypes of ES change}

The cluster analysis resulted in seven clusters hereafter labelled Clusters A through $G$, which defined a meaningful typology of ES change. Clusters $\mathrm{A}$ and $\mathrm{B}$ were characterized by increases in land-use intensity; all cases in Cluster A related to the expansion of 
agriculture and most cases in Cluster $\mathrm{B}$ related to expansion of forest plantations and cities over areas formerly dominated by extensive agriculture (Table 2). In contrast, Clusters $\mathrm{C}, \mathrm{D}$, and $\mathrm{E}$ described decreases in land-use intensity due to reduced agricultural activities, land abandonment, or restoration, resulting in a variety of post-agricultural ES dynamics with differing implications for regulating and cultural services. Most clusters from $\mathrm{A}$ to $\mathrm{E}$ highlighted trade-offs between provisioning and other services and underscored a diversity of such trade-offs, with $\mathrm{D}$ also showing tradeoffs between regulating and cultural services. Cluster $F$ encompassed cases where all three ES groups decreased, whereas Cluster $G$ was composed of cases for which ES changes were either unreported or limited (for this reason, we did not consider an archetype associated with Cluster G). We describe each archetype in turn below before considering this typology as a model for ES change.

\section{Archetype A: agricultural development}

Cluster A described increases in food production at the expense of regulating and cultural services, as exemplified by cases of agriculture expansion. An archetypal case was the agricultural expansion on paramos (alpine grassland of South American uplands) and cloud forests of Ecuador from 1963 to 1991, which broadly decreased timber, soil and water services, carbon, and recreation (Balthazar et al. 2015). Most cases in this cluster were located in developing countries (eg Kenya, Nepal, and Ethiopia) and were driven by increasing demand for food from expanding human populations or markets. Considering the substantial expansion of global agricultural activity over the past 40 years (Laurance et al. 2014), it is notable that this cluster accounts for only a small fraction of our cases of ES change (Table 2).

\section{Archetype B: shift from food to other products}

Cluster B included cases describing the intensification of timber production, which often led specifically to the degradation of soil and water services. Increased timber production is typically achieved by plantation reforestation over grasslands or low-intensity croplands. The expansion of conifer plantations on grasslands, for example in the Araucania region of Chile (Geneletti 2013) and the Ecuadorian highlands (Farley 2007), increased the provision of timber and in some cases carbon, but the replacement of native grasslands by ecologically simple plantations greatly reduced soil protection and water infiltration. The expansion of intensive timber plantations is frequently an extension of earlier agricultural expansion, both conceptually and practically (Sloan 2016), and as such cases in Cluster B may

Table 2. Description of the seven clusters of ES dynamics in mountains

\begin{tabular}{|c|c|c|c|c|c|}
\hline Cluster & $n$ (n robust) & $\begin{array}{l}\text { Provisioning } \\
\text { services }\end{array}$ & $\begin{array}{l}\text { Regulating } \\
\text { services }\end{array}$ & Cultural services & Main landscape changes \\
\hline $\begin{array}{l}\text { (A) Agricultural } \\
\text { development }\end{array}$ & $7(7)$ & More food & Less regulating & Less cultural & $\begin{array}{l}\text { Cropland intensification or } \\
\text { expansion (or grassland } \\
\text { intensification in some cases) }\end{array}$ \\
\hline $\begin{array}{l}\text { (B) Shift from food } \\
\text { to other products }\end{array}$ & $8(4)$ & $\begin{array}{l}\text { Shift from food } \\
\text { to timber and } \\
\text { other products }\end{array}$ & $\begin{array}{l}\text { Fewer soil and } \\
\text { water services }\end{array}$ & No change & $\begin{array}{l}\text { Expansion of forest plantations, } \\
\text { urbanization }\end{array}$ \\
\hline $\begin{array}{l}\text { (C) From food to } \\
\text { regulating services }\end{array}$ & II (5) & Less food & More regulating & No change & $\begin{array}{l}\text { Agricultural extensification; land } \\
\text { abandonment; natural vegetation } \\
\text { regrowth }\end{array}$ \\
\hline $\begin{array}{l}\text { (D) From food to } \\
\text { more regulating } \\
\text { but fewer cultural } \\
\text { services }\end{array}$ & $7(7)$ & Less food & More regulating & Less cultural & $\begin{array}{l}\text { Agricultural extensification; land } \\
\text { abandonment; natural vegetation } \\
\text { regrowth; restoration }\end{array}$ \\
\hline $\begin{array}{l}\text { (E) Fewer products } \\
\text { and sometimes } \\
\text { more recreation }\end{array}$ & $8(7)$ & $\begin{array}{l}\text { Less food or } \\
\text { less provisioning } \\
\text { in general }\end{array}$ & No change & $\begin{array}{l}\text { More recreation } \\
\text { or no changes }\end{array}$ & $\begin{array}{l}\text { Agricultural extensification; land } \\
\text { abandonment; rewilding }\end{array}$ \\
\hline $\begin{array}{l}\text { (F) Worst-case } \\
\text { scenarios }\end{array}$ & $3(3)$ & Less provisioning & Less regulating & Less cultural & $\begin{array}{l}\text { Urbanization; invasive species; } \\
\text { reduction or degradation of forests, } \\
\text { grasslands, and wetlands }\end{array}$ \\
\hline $\begin{array}{l}\text { (G) Limited or } \\
\text { unclear changes }\end{array}$ & $7(7)$ & No change & No change & No change & $\begin{array}{l}\text { Urbanization; effects of } \mathrm{CO}_{2} \\
\text { increase; extensification }\end{array}$ \\
\hline
\end{tabular}

Notes: "No change" means limited or unclear changes or missing data, $n$ is the number of cases belonging to this cluster according to the majority rule (ie the cluster most frequently determined by a set of clustering options), and " $n$ robust" is the number of cases belonging to this cluster according to a robust rule (ie the cluster determined by more than two-thirds of the clustering options). 
develop in close geographic and temporal proximity to cases in Cluster A. In most cases in Cluster B, land-use dynamics were driven by timber markets and forest policies that incentivized plantations for addressing forest product scarcity, reducing pressure on natural forests and sequestering carbon.

\section{Archetype C: from food to regulating services}

Cluster C involved an increase in regulating services with a concurrent decrease in agricultural production but without consistent changes in cultural services. In Switzerland (Briner et al. 2013), for instance, and in the Pamir, Altai, and Tian Shan mountains of Central Asia (Chen et al. 2013), drivers were generally linked to an increased demand for regulating services (carbon, water quality, water flow regulation) through environmental policies and a decreased demand for food through agricultural and trade policies or greater competiveness of other regions worldwide.

\section{Archetype D: from food to more regulating but fewer cultural services}

Similar to Cluster C, Cluster D was associated with increased regulating services and decreased agricultural production; yet unlike Cluster C, cultural services were noticeably reduced in Cluster D. For example, in a hypothetical scenario for marginal upland peatlands in the UK, restoration would lead to a decrease in sheep stocking densities (provisioning service) and improved buffering of water peak flows (regulating service) but would negatively affect species of conservation concern and recreational activities (eg hill walking, deer hunting, or horse riding) (Grand-Clement et al. 2013). Drivers included changes in markets and agricultural and environmental policies, as well as socioeconomic changes (eg migration from rural to urban areas).

\section{Archetype E: fewer products and sometimes more recreation}

Cluster E was characterized by a decrease in multiple provisioning services (such as food and timber) and an increase in cultural (specifically recreation) services, with drivers similar to those in Cluster D. In the Cantabrian Mountains of Spain, for instance, urbanization and industrialization have led to the abandonment of traditionally managed heath-pasture mosaics, which has increased the value of the landscape for recreation and tourism activities while simultaneously decreasing its value for agricultural production and heritage (MoránOrdóñez et al. 2013). In light of the probability that heritage and recreation appeal to different groups of people, this trade-off may have major implications for equity, for example between local people losing their heritage values and visitors gaining recreation opportunities.

\section{Archetype F: worst-case scenarios}

Cluster $\mathrm{F}$ described declines in all three groups of ES. For example, the degradation of grasslands and wetlands in China's Zoige Plateau - due to overgrazing, excessive land reclamation for agriculture, and misuse of water resources ( $\mathrm{Li}$ et al. 2010) - reduced food and timber, carbon storage, water and soil regulation, and cultural values. Such generalized decline is typically attributable to poor environmental management and leads to ecological collapse with "cascading" effects. There was, however, neither an apparent pattern of causation (sequence of ES change) among provisioning and regulating services in the case studies nor evidence of so-called "vicious circles" (for instance, when an initial degradation of regulating services causes the loss of provisioning services and stimulates a further compensatory intensification in provisioning services, which in turn degrades ecosystem productivity further, thereby initiating a negative feedback).

\section{Discussion}

In light of the paucity of studies to date, our synthesis fills critical knowledge gaps concerning the nature and diversity of multiple ES trade-offs over time in mountainous landscapes (Seppelt et al. 2011; Lee and Lautenbach 2015). Given that the ES-change trajectories among the 51 cases spanned a variety of ecological and socioeconomic contexts as well as landscape configurations and uses, we assume that our typology encompasses virtually all major trajectories of ES changes in mountain landscapes. We therefore propose revisions to current conceptual models of multiple ES change over time.

\section{Land-use intensity and ES}

Land-use intensity was an important factor shaping the archetypes of ES change. Archetypes A through E were distinguished according to whether intensification $(\mathrm{A}-\mathrm{B})$ or extensification $(\mathrm{C}-\mathrm{E})$ predominated. The ES trade-offs across the archetypes align with the stylized model proposed by Braat and Ten Brink (2008) and De Groot et al. (2010) (Figure 1), with certain caveats. First, the positive effects of land-use extensification on regulating and cultural services were variable (Archetypes $\mathrm{C}-\mathrm{E}$ in Figure 1), underscoring the key roles of political, socioeconomic, and cultural contexts in shaping ES trade-offs. Second, the tradeoffs entailed by land-use intensification varied according to whether agriculture or combined forestry-agricultural activities predominated, 

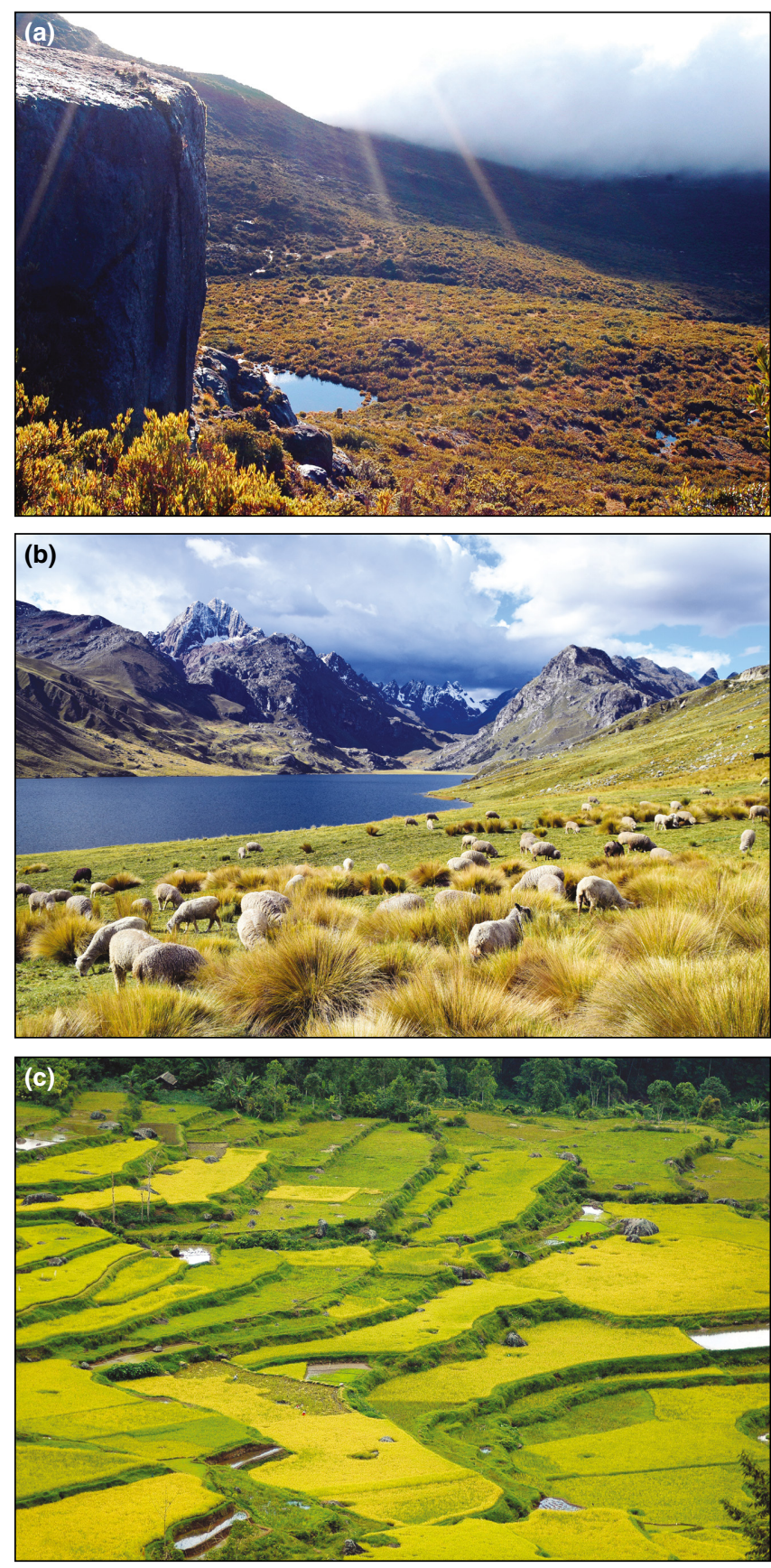

Figure 2. Mountain landscapes with grass-dominated ecosystems along a gradient of land-use intensity: from natural and light use ([a] Chirripó National Park, Costa Rica) to extensive ([b] Cordillera Blanca, Peru) and intensive ([c] Sulawesi Highlands, Indonesia).

suggesting an evolution of trade-offs over the course of a landscape's exploitation. Finally, trade-offs varied greatly depending on whether grassland or forest biomes occurred in a landscape (Figures 2 and 3). We elaborate these caveats below to refine a conceptual model of ES change in mountainous landscapes on the basis of the archetypes.

The adjustments to the model (Figure 4) reflect a distinction - implicit in our typology (eg between cases
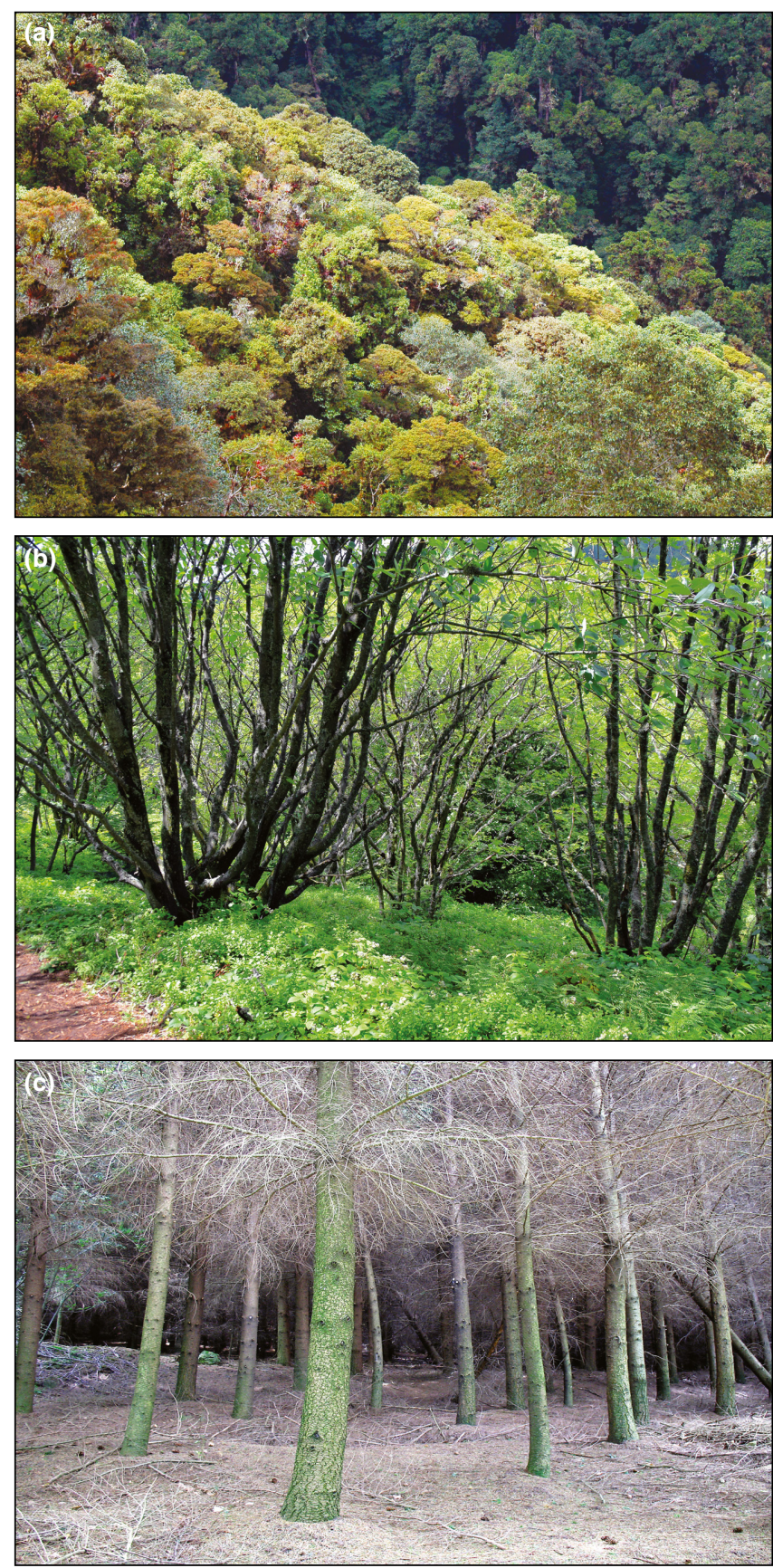

Figure 3. Mountain landscapes with tree-dominated ecosystems along a gradient of land-use intensity: from natural and light use ([a] Tapantí National Park, Costa Rica) to extensive ([b] Pilat Mountains, France) and intensive ([c] Pilat Mountains, France).

in Clusters A and B) - between grassland and treedominated ecosystems as well as between trajectories of change to carbon sequestration and to soil and water services (De Groot et al. 2010). Soil and water services may decline comparably between intensive agriculture and forestry operations but carbon sequestration potential will differ greatly, particularly between natural grassland and forest biomes (Su et al. 2012; Geneletti 2013). Indeed, whether in grassland or forest, both 


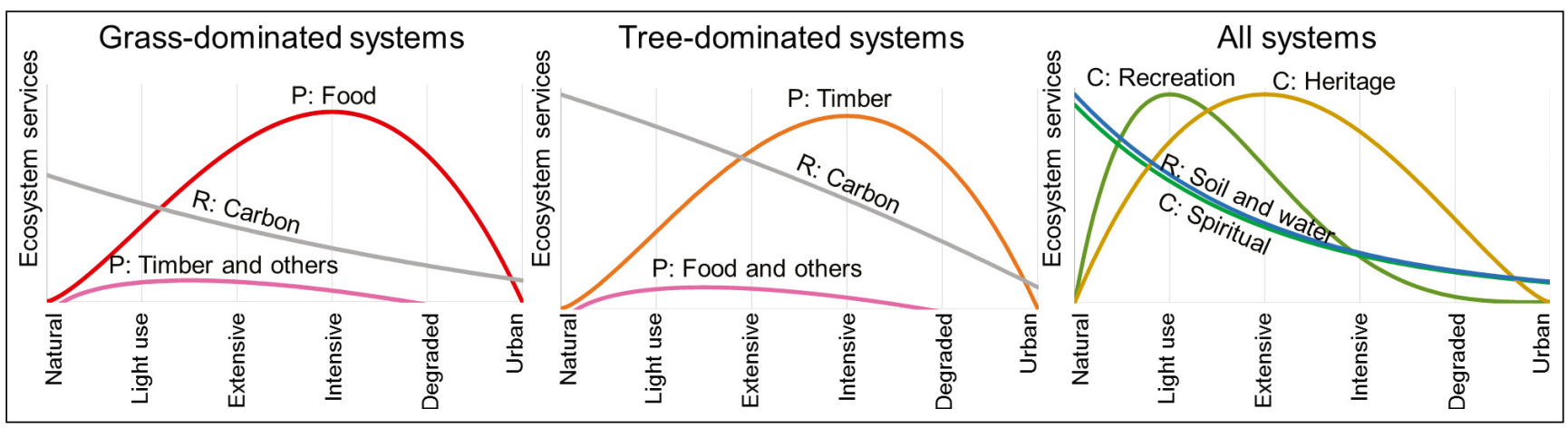

Figure 4. Adjustments to the model by Braat and Ten Brink (2008) and De Groot et al. (2010) in the case of grass-dominated systems (left), tree-dominated systems (center), and all systems (right). $P=$ provisioning services; $R=$ regulating services; $\mathrm{C}=$ cultural services.

trajectories of intensification entail concurrent declines in most ES, except for those services targeted by intensification (food or timber) and, to a lesser extent, carbon (Figure 4). Although targeting agricultural expansion in savanna biomes is sometimes proposed to spare development of the supposedly more ecologically valuable and carbon-rich forest biomes, this expansion may degrade multiple ES and fine-scale analyses should be used to identify potential sites that have the least harmful outcomes if developed (Searchinger et al. 2015).

Our amendments to the model (Figure 4) also reveal the variable dynamics of cultural services, particularly heritage values that were not well depicted by the simple model. One reason for this is the difficulty of generalizing cultural services, which are highly context specific (Daniel et al. 2012). Another reason is that the heritage values of many anthropogenic landscapes are maintained by active land management and decrease with extensification or land abandonment. The revised model considers high heritage values in managed landscapes and decreases in such values with landscape abandonment or degradation and urbanization (Figure 4). Whether the highest heritage values are

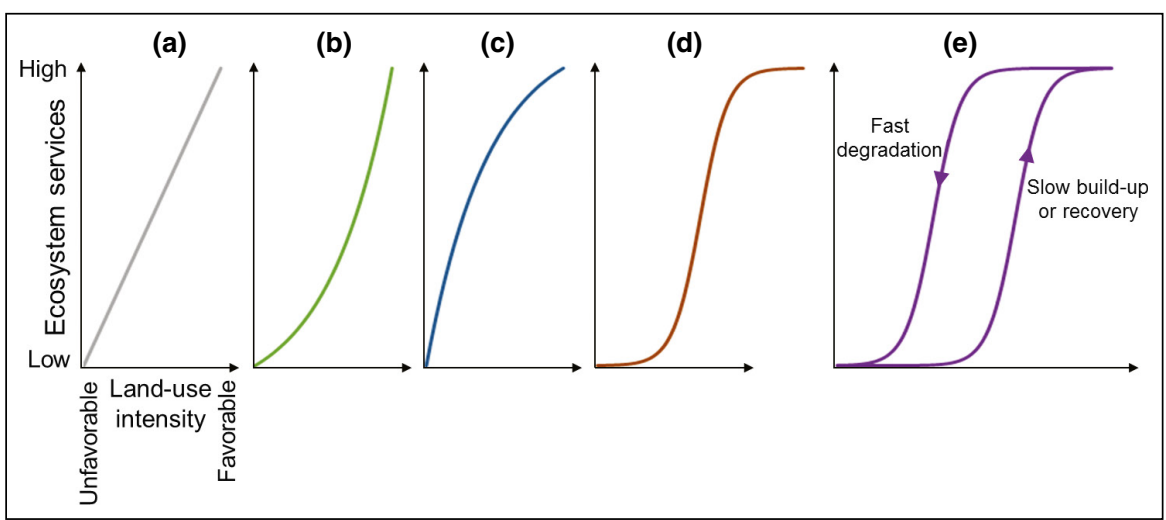

Figure 5. Possible relationships between land-use intensity and ecosystem services: (a) linear, (b) convex, (c) concave, (d) sigmoid with thresholds, and (e) double sigmoid with hysteresis. found in extensively or intensively managed landscapes is questionable, given that such values are often contextdependent (eg intensively cultivated rice terraces can have high heritage values).

Although the adjusted model captures the dynamics of ES in the broad archetypes identified in our study, we note three caveats: (1) specific cases may differ from the model because of local peculiarities attributed to certain services, (2) the model fails to capture the entire complexity of how services respond along the gradient of land-use intensification, and (3) the model is value laden with regard to particular ES. For instance, urban landscapes represent a mix of land-use intensities, and some urban designs might have more favorable impacts on some services than others, as well as in different locations. Indeed, urban ecosystems may provide important provisioning services and a variety of cultural services.

At the local scale, idiosyncratic trade-offs between ES may be influenced by management practices. For example, agricultural intensification based on sound management practices does not necessarily degrade water and soil services as shown by Cluster A cases (Bommarco et al. 2013), and timber production can be increased through managed regrowth, agroforestry, and mixed plantations of native species, with generally less severe effects on water, soil, and biodiversity than in Cluster B cases (Farley 2007; Rudel 2010). Actual trade-offs may differ from those presented in the stylized model because of the existence of mixed systems (ie neither grass-dominated nor tree-dominated). For example, agroforestry systems have been proposed for sustainable intensification (ie increasing production of goods without causing undue degradation to natural resources; Shriar 2000). 


\section{Thresholds and hysteresis in ES dynamics}

Our limited understanding of non-linear, temporally lagged dynamics in ES trade-offs remains a major scientific challenge (Bennett et al. 2015). Conceptual depictions of smooth ES curves across different levels of land-use intensity (Figures 1 and 4) are ultimately only illustrative of the general direction of change, which may in fact assume a variety of non-linear forms (Figure 5, a-c) or may indicate abrupt changes (Figure $5 \mathrm{~d}$ ), as illustrated in the case of soil-related services (Labrière et al. 2015).

Simple conceptual models and related relationships between land use and ES have implicitly assumed that the degradation of an ES following a given degree of landuse intensification may be reversed by an equal degree of subsequent land-use extensification (Wright and MullerLandau 2006). In reality, relationships between land-use intensity and the state of ES are typically not bidirectional because of system hysteresis (ie the fact that past system history affects current system state) (Figure 5e; Walker et al. 2012).

The degree to which relationships are bi-directional depends greatly on both the ES in question and its degree of degradation but also on temporal lags, which are not reflected in conceptual models. For example, soil properties, erosion control, and water infiltration are relatively amenable to recovery upon extensification, albeit with a major time lag (Bruijnzeel 2004), whereas biodiversity may not recover or may advance toward a new state. Biodiversity recovery may fail to occur despite complete land abandonment if fauna previously accumulated "extinction debts" during sustained periods of habitat degradation (Kuussaari et al. 2009). Different velocities of changes in ES also occur with heritage values. Where landscapes have been traditionally managed by rural activities, extensification can lead to land abandonment and the rapid loss of landscape-associated heritage values (Navarro and Pereira 2015), which had accumulated over decades or centuries of previous land management and resulted from a coevolution between landscapes and societies (Gómez-Sal et al. 2003).

\section{Scale issues}

Further analyses of the links between land-use intensification and ES should consider scale and landscape heterogeneity (Grêt-Regamey et al. 2014). We described mountain landscape trajectories by their dominant landuse change (in terms of land-use intensity and vegetation type), yet landscapes invariably include a combination of different land uses of varying intensities and with interrelated dynamics at multiple scales. Agricultural intensification in some parts of a mountain landscape may coincide with - if not encourage rewilding in other areas, and this "land-sparing" dynamic can also occur within smaller units such as farms
(Balmford et al. 2012). Extensification in mountains may be possible only because agricultural intensification occurs in the lowlands (Habel et al. 2013). The net effects on ES of such "nested" intensification and extensification within larger landscapes remain highly uncertain. ES dynamics need to be considered at different scales, including outside mountain areas, in order to understand mountain landscape trajectories.

\section{Conclusion}

We investigated how past and future land-use trajectories influence multiple ES over time, using mountain landscapes as a model. Our analysis revealed several archetypes of ES trajectories and highlighted the importance of land-use intensity in driving concurrent changes to multiple services. The trade-offs between services identified by these archetypes are consistent with output from the model proposed by Braat and Ten Brink (2008) and De Groot et al. (2010), and suggest possible revisions to that model. Our revised stylized model - depicting changes to ES along a gradient of land-use intensity in mountains - could be tested and adjusted to other contexts, such as drylands and the humid tropics. Due to its relative simplicity, our model can be used to communicate scientific findings regarding trade-offs to practitioners and policy makers but should be modified to account for distinctive local features before application within specific contexts.

\section{Acknowledgements}

This research was supported by the International Climate Initiative (IKI) of the German Federal Ministry for the Environment, Nature Conservation, Building and Nuclear Safety (BMUB), the CGIAR Research Program on Forests, Trees and Agroforestry (CRPFTA) with financial support from the CGIAR Fund, and the BiodivERsA project REGARDS, with support from the French Agence Nationale pour la Recherche (ANR-12-EBID-004-01) and the FWF Austrian Science Fund (I 1056-B25). We thank the Mountain Research Initiative, which initiated this study in a workshop held in Switzerland in 2012.

\section{References}

Asner GP, Rudel TK, Aide TM, et al. 2009. A contemporary assessment of change in humid tropical forests. Conserv Biol 23: 1386-95.

Balmford A, Green R, and Phalan B. 2012. What conservationists need to know about farming. P Roy Soc B-Biol Sci 279: 271424.

Balthazar V, Vanacker V, Molina A, et al. 2015. Impacts of forest cover change on ecosystem services in high Andean mountains. Ecol Indic 48: 63-75.

Bennett EM, Cramer W, Begossi A, et al. 2015. Linking biodiversity, ecosystem services, and human well-being: three challenges for designing research for sustainability. Curr Opin Environ Sustain 14: 76-85. 
Bennett EM, Peterson GD, and Gordon LJ. 2009. Understanding relationships among multiple ecosystem services. Ecol Lett 12: $1-11$.

Bommarco R, Kleijn D, and Potts SG. 2013. Ecological intensification: harnessing ecosystem services for food security. Trends Ecol Evol 28: 230-38.

Braat L and Ten Brink P (Eds). 2008. The cost of policy inaction: the case of not meeting the 2010 biodiversity target. Wageningen, the Netherlands: Institute for European Environmental Policy. Study for the European Commission, DG Environment. Alterra report 1718.

Briner S, Elkin C, and Huber R. 2013. Evaluating the relative impact of climate and economic changes on forest and agricultural ecosystem services in mountain regions. J Environ Manage 129: 414-22.

Bruijnzeel LA. 2004. Hydrological functions of tropical forests: not seeing the soil for the trees? Agr Ecosyst Environ 104: $185-228$

Burkhard B, Kroll F, Müller F, et al. 2009. Landscapes' capacities to provide ecosystem services - a concept for land-cover based assessments. Landscape Online 15: 22.

Charrad M, Ghazzali N, Boiteau V, et al. 2014. NbClust package: finding the relevant number of clusters in a dataset. J Stat Softw 61: $1-36$.

Chen X, Bai J, Li X, et al. 2013. Changes in land use/land cover and ecosystem services in Central Asia during 1990-2009. Curr Opin Environ Sustain 5: 116-27.

Crouzat E, Mouchet M, Turkelboom F, et al. 2015. Assessing bundles of ecosystem services from regional to landscape scale: insights from the French Alps. J Appl Ecol 52: 114555.

Daniel TC, Muhar A, Arnberger A, et al. 2012. Contributions of cultural services to the ecosystem services agenda. P Natl Acad Sci USA 109: 8812-19.

De Groot RS, Alkemade R, Braat L, et al. 2010. Challenges in integrating the concept of ecosystem services and values in landscape planning, management and decision making. Ecol Complex 7: 260-72.

Erb K-H, Haberl H, Jepsen MR, et al. 2013. A conceptual framework for analysing and measuring land-use intensity. Curr Opin Environ Sustain 5: 464-70.

Farley KA. 2007. Grasslands to tree plantations: forest transition in the Andes of Ecuador. Ann Assoc Amer Geogr 97: 75571.

Flynn DF, Gogol-Prokurat M, Nogeire T, et al. 2009. Loss of functional diversity under land use intensification across multiple taxa. Ecol Lett 12: 22-33.

Foley JA, DeFries R, Asner GP, et al. 2005. Global consequences of land use. Science 309: 570-74.

Geneletti D. 2013. Assessing the impact of alternative land-use zoning policies on future ecosystem services. Environ Impact Asses 40: 25-35.

Gómez-Sal A, Belmontes J-A, and Nicolau J-M. 2003. Assessing landscape values: a proposal for a multidimensional conceptual model. Ecol Model 168: 319-41.

Grand-Clement E, Anderson K, Smith D, et al. 2013. Evaluating ecosystem goods and services after restoration of marginal upland peatlands in south-west England. J Appl Ecol 50: 324-34.

Grêt-Regamey A, Brunner SH, and Kienast F. 2012. Mountain ecosystem services: who cares? Mt Res Dev 32: S23-34.

Grêt-Regamey A, Rabe S-E, Crespo R, et al. 2014. On the importance of non-linear relationships between landscape patterns and the sustainable provision of ecosystem services. Landscape Ecol 29: 201-12.

Habel J, Weisser W, Eggermont H, et al. 2013. Food security versus biodiversity protection: an example of land-sharing from East Africa. Biodivers Conserv 22: 1553-55.
Holland RA, Eigenbrod F, Armsworth PR, et al. 2011. The influence of temporal variation on relationships between ecosystem services. Biodivers Conserv 20: 3285-94.

Kleijn D, Kohler F, Báldi A, et al. 2009. On the relationship between farmland biodiversity and land-use intensity in Europe. P Roy Soc B-Biol Sci 276: 903-09.

Klein AM, Steffan-Dewenter I, Buchori D, et al. 2002. Effects of land-use intensity in tropical agroforestry systems on coffee flower-visiting and trap-nesting bees and wasps. Conserv Biol 16: $1003-14$.

Kuussaari M, Bommarco R, Heikkinen RK, et al. 2009. Extinction debt: a challenge for biodiversity conservation. Trends Ecol Evol 24: 564-71.

Labrière N, Locatelli B, Laumonier Y, et al. 2015. Soil erosion in the humid tropics: a systematic quantitative review. Agr Ecosyst Environ 203: 127-39.

Lambin EF and Meyfroidt P. 2011. Global land use change, economic globalization, and the looming land scarcity. P Natl Acad Sci USA 108: 3465-72.

Lambin EF, Rounsevell M, and Geist H. 2000. Are agricultural land-use models able to predict changes in land-use intensity? Agr Ecosyst Environ 82: 321-31.

Laurance WF, Sayer J, and Cassman KG. 2014. Agricultural expansion and its impacts on tropical nature. Trends Ecol Evol 29: 107-16.

Lautenbach S, Kugel C, Lausch A, et al. 2011. Analysis of historic changes in regional ecosystem service provisioning using land use data. Ecol Indic 11: 676-87.

Lee $\mathrm{H}$ and Lautenbach S. 2015. A quantitative review of relationships between ecosystem services. Ecol Indic 66: 340-51.

Levers C, Müller D, Erb K, et al. 2015. Archetypical patterns and trajectories of land systems in Europe. Reg Environ Change; doi:10.1007/s10113-015-0907-x.

Li J, Wang W, Hu G, et al. 2010. Changes in ecosystem service values in Zoige Plateau, China. Agr Ecosyst Environ 139: 76670.

Locatelli B, Imbach P, and Wunder S. 2014. Synergies and tradeoffs between ecosystem services in Costa Rica. Environ Conserv 41: 27-36.

MA (Millennium Ecosystem Assessment). 2005. Ecosystems and human well-being: synthesis report. Washington, DC: Island Press.

Marston RA. 2008. Land, life, and environmental change in mountains. Ann Assoc Amer Geogr 98: 507-20.

Morán-Ordóñez A, Bugter R, Suárez-Seoane S, et al. 2013. Temporal changes in socio-ecological systems and their impact on ecosystem services at different governance scales: a case study of heathlands. Ecosystems 16: 765-82.

Navarro LM and Pereira HM. 2015. Rewilding abandoned landscapes in Europe. In: Pereira HM and Navarro LM (Eds). Rewilding European landscapes. New York, NY: Springer International Publishing.

R Core Team. 2014. R: a language and environment for statistical computing, version 3.2.2. Vienna, Austria: R Foundation for Statistical Computing. https://www.R-project.org.

Raudsepp-Hearne C, Peterson G, and Bennett E. 2010. Ecosystem service bundles for analyzing tradeoffs in diverse landscapes. $P$ Natl Acad Sci USA 107: 5242-47.

Renard D, Rhemtulla JM, and Bennett EM. 2015. Historical dynamics in ecosystem service bundles. P Natl Acad Sci USA 112: 13411-16.

Rudel TK. 2010. Three paths to forest expansion: a comparative historical analysis. In: Nagendra $\mathrm{H}$ and Southworth J (Eds). Reforesting landscapes. Dordrecht, the Netherlands: Springer.

Schirpke U, Leitinger G, Tasser E, et al. 2013. Multiple ecosystem services of a changing Alpine landscape: past, present 
and future. Int J Biodivers Sci Ecosystem Services Manage 9: 123-35.

Schneiders A, Van Daele T, Van Landuyt W, et al. 2012. Biodiversity and ecosystem services: complementary approaches for ecosystem management? Ecol Indic 21: 12333.

Schnell S, Altrell D, Ståhl G, et al. 2015. The contribution of trees outside forests to national tree biomass and carbon stocks - a comparative study across three continents. Environ Monit Assess 187: 1-18.

Searchinger TD, Estes L, Thornton PK, et al. 2015. High carbon and biodiversity costs from converting Africa's wet savannahs to cropland. Nature Climate Change 5: 481-86.

Seppelt R, Dormann CF, Eppink FV, et al. 2011. A quantitative review of ecosystem service studies: approaches, shortcomings and the road ahead. J Appl Ecol 48: 630-36.

Seppelt R, Lautenbach S, and Volk M. 2013. Identifying tradeoffs between ecosystem services, land use, and biodiversity: a plea for combining scenario analysis and optimization on different spatial scales. Curr Opin Environ Sustain 5: 458-63.

Shriar A. 2000. Agricultural intensity and its measurement in frontier regions. Agroforest Syst 49: 301-18.

Sloan S. 2016. Tropical forest gain and interactions amongst agents of forest change. Forests 7: 55.

Su S, Xiao R, Jiang Z, et al. 2012. Characterizing landscape pattern and ecosystem service value changes for urbanization impacts at an eco-regional scale. Appl Geogr 34: 295-305.

Swift MJ, Izac AMN, and van Noordwijk M. 2004. Biodiversity and ecosystem services in agricultural landscapes - are we asking the right questions? Agr Ecosyst Environ 104: 113-34.

Tscharntke T, Klein AM, Kruess A, et al. 2005. Landscape perspectives on agricultural intensification and biodiversity-ecosystem service management. Ecol Lett 8: 857-74.

Turner BL and Doolittle WE. 1978. The concept and measure of agricultural intensity. Prof Geogr 30: 297-301.

Walker BH, Carpenter SR, Rockstrom J, et al. 2012. Drivers, "slow" variables, "fast" variables, shocks, and resilience. Ecol Soc 17: $\operatorname{art30.}$

Wright SJ and Muller-Landau HC. 2006. The future of tropical forest species. Biotropica 38: 287-301.

Zimmermann P, Tasser E, Leitinger G, et al. 2010. Effects of land-use and land-cover pattern on landscape-scale biodiversity in the European Alps. Agr Ecosyst Environ 139: $13-22$.

\section{Supporting Information}

Additional, web-only material may be found in the online version of this article at http://onlinelibrary. wiley.com/doi/10.1002/fee.1470/suppinfo

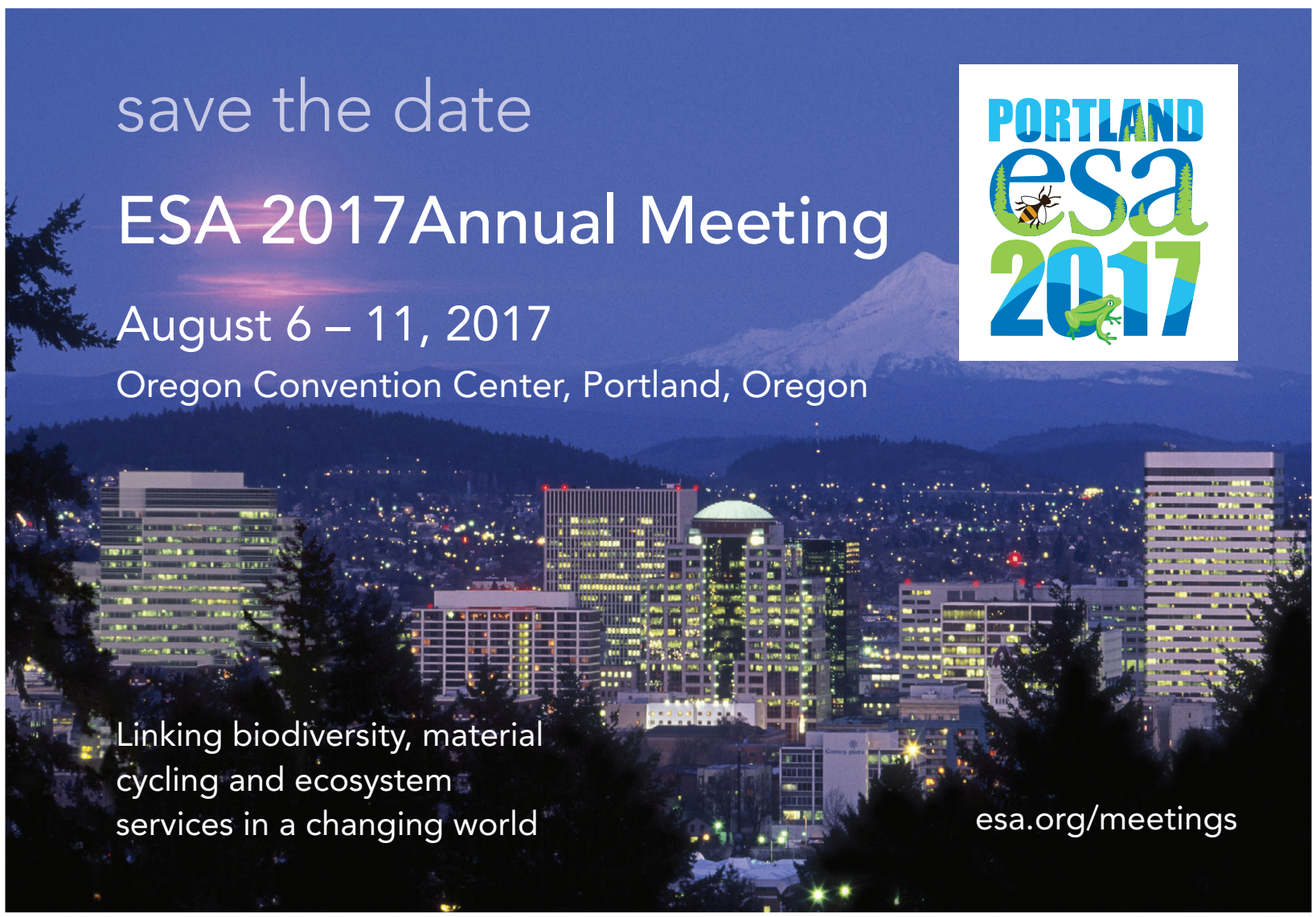

